\title{
Does Gensia's Arasine help heart patients?
}

NEW YORK-Last September, when Gensia Pharmaceuticals (San Diego, CA) reported disappointing preliminary results from phase III clinical trials of its heart-surgery drug, Arasine, its stock plummeted 38 percent, knocking \$381 million off its market valuation. Not surprisingly, Gensia's recent reporting of Arasine's completeand still disappointing - phase III results did nothing to boost its stillpummeled stock. As one biotech analyst puts it, "There's a drug buried somewhere in Gensia's data, but Gensia will have to generate a lot more data to show where it is."

Arasine's phase III trial involved patients undergoing coronary artery bypass grafting (CABG). Arasine - a purine nucleoside ana$\log$ - acts by increasing the level of naturally occurring adenosine in tissue suffering a loss of blood. Adenosine, in turn, protects such tissue by increasing vasodilation and minimizing white-blood-cell movement. For its part, CABG is a surgical technique that uses a vein or an artery as a graft to bypass an atherosclerotic block in a coronary artery. The graft then delivers blood from the aorta to a point beyond the arterial blockage. Yet, in the U.S. alone, up to 15 percent of CABG patients-or over 50,000 individuals-annually suffer heart attacks during the procedure. Largely because of extra intensive-care therapy, these heart attacks can cost as much as $\$ 15,000$ a patient.

\section{U.S. trial}

Arasine's phase III trial actually consisted of two studies, with one performed in the U.S. and the other performed internationally. In the U.S. study, 633 CABG patients received either placebo, low doses of Arasine, or high doses of Arasine. Low doses were made up of 0.05 $\mathrm{mg} / \mathrm{kg} / \mathrm{min}$ infusions of Arasine, while high doses consisted of 0.1 $\mathrm{mg} / \mathrm{kg} / \mathrm{min}$ Arasine infusions. One of the study's primary endpoints was heart attacks, which were defined as the presence of electrocardiogram changes, the presence of the heart-muscle enzyme creatinine kinase (CK-MB), or the presence of heart attack at autopsy. The study's other primary endpoint- which overlapped with the heartattack endpoint - was adverse cardiovascular outcomes, including stroke, heart attack, cardiac death, congestive heart failure, or lifethreatening arrhythmia.

Arasine showed no statistically significant benefit when measured by the study's primary endpoints. The heart-attack endpoint found that 24 percent of placebo patients suffered heart attacks, while 26 percent of low-dose patients had them and 21 percent of high-dose patients had them. The adverse-cardiovascular-outcomes endpoint showed that 30 percent of placebo patients had such outcomes, with 30 percent of low-dose patients having them and 22 percent of highdose patients having them.

Gensia, however, then changed the study's endpoints. Indeed, by simply changing the definition of a heart attack, Gensia radically changed the study's results. Gensia now defined heart attacks as the presence of electrocardiogram changes and the presence of CKMB or the presence of heart attack at autopsy. This is a more specific and clinically rigorous definition, since diagnosing heart attacks during $C A B G$ presents difficulties, as patients are under anesthesia and, thus, unable to report chest pain.

The new heart-attack endpoint showed that 5.2 percent of placebo patients suffered heart attacks, 4.2 percent of low-dose patients had them, and 1.4 percent of high-dose patients had them. High-dose patients showed a statistically significant 72 percent drop in heart attacks, compared to placebo patients. The new adverse-cardiovascularoutcomes endpoint found that 14 percent of placebo patients had these outcomes, while 10 percent of lowdose patients had them and 5 percent of high-dose patients had them. Compared to placebo, high-dose patients had a statistically significant 62 percent cut in adverse outcomes.

\section{International trial}

In the international trial, Arasine didn't show statistical significance against either the original endpoints or the new endpoints. The studyconducted in Canada and seven
European countries-involved 821 CABG patients, who received placebo or high doses of Arasine. The original heart-attack endpoint showed that 29 percent of placebo patients suffered heart attacks and that 27 percent of high-dose patients had them. The original adverse-cardiovascular-outcomes endpoint found that 31 percent of placebo patients had such outcomes, while 30 percent of high-dose patients had them. Under the new heart-attack endpoint, 7 percent of placebo patients suffered heart attacks, and 5 percent of high-dose patients suffered them. And under the new adverse-cardiovascularoutcomes endpoint, 11 percent of both placebo patients and high-dose patients had these outcomes.

Yet the international trial was riddled with problems. While all patient drugs, anesthetics, and procedures were standardized in the U.S. trial, they weren't standardized in the international study. Also, the CK-MB samples were poorly handled in the international trial.

Gensia has filed a new drug application (NDA) with the Food and Drug Administration (FDA, Bethesda, MD). It has also filed for Arasine marketing approval in Europe and Canada. Gensia is currently conducting a third phase III trial of Arasine, which it expects to complete next year. The trial-ongoing in the U.S. and Canada-will involve about $1,000 \mathrm{CABG}$ patients. One of the endpoints is heart attacks, which Gensia defines as the presence of electrocardiogram changes and the presence of CK$\mathrm{MB}$ or the presence of heart attack at autopsy. The other endpoint is adverse cardiovascular outcomes, including heart attack, cardiac death, and stroke.

Most likely, FDA will await the results of Arasine's third phase III trial before completing action on the product's NDA. This will delay hoped-for approval of Arasine until 1995 or 1996. Yet at least one biotech analyst sees Arasine reaching both the U.S. and European markets in 1995. Gregory Brown of Vector Securities International (Deerfield, IL) forsees Arasine achieving \$57 million in worldwide sales that year. -B.J.Spalding
"There's a

drug buried

somewhere in

Gensia's data,

but Gensia

will have to

generate a lot

more data

to show

where it is." 